\title{
Plano Estratégico de Pagamento por Serviços Ambientais na bacia hidrográfica do Arroio Itaquarinchim (RS): integrando responsabilidades
}

\author{
Strategic payment plan for environmental services in \\ Itaquarinchim Arroyo Basin, RS: integrating responsibilities
}

Alice da Costa Palagi', Camila Dalla Porta Mattiuzi', Dieter Wartchow* (1), Liesbet Olaerts ${ }^{1}$

\begin{abstract}
RESUMO
O presente trabalho tem por objetivo desenvolver um Plano Estratégico de Pagamento por Serviços Ambientais (PEPSA) para a manutenção da qualidade da água e do solo na bacia hidrográfica do arroio Itaquarinchim, em Santo Ângelo (RS). Com base em um diagnóstico ambiental da bacia hidrográfica, das ações propostas no Plano Municipal de Saneamento Básico e do Plano da Bacia Hidrográfica do Rio ljuí, foram levantados os principais problemas ambientais existentes na bacia, definidos possíveis serviços ambientais e apontados seus benefícios. O PEPSA propõe uma análise integrada das políticas relacionadas aos recursos hídricos, relacionando-as com as metas e os objetivos dos planos analisados. Com o intuito de efetivar as ações propostas, o PEPSA sugere, após identificar possíveis fontes de recursos, a formatação de um fundo para pagamento de serviços ambientais. O PEPSA organizado de forma sistêmica pode ser compreendido como ferramenta base para a concretização de ações e metas propostas em diferentes planos e programas e, dessa forma, para a efetivação de políticas públicas.
\end{abstract}

Palavras-chave: serviços ambientais; pagamento; bacia hidrográfica; manejo integrado de recursos hídricos; arroio Itaquarinchim.

\begin{abstract}
This paper aims to develop a Strategic Payment Plan for Environmental Services (SPPES), for the maintenance of water and soil quality in the watershed of Arroyo Itaquarinchim, in St. Angelo/RS. Based on an environmental assessment of the river basin, of the actions proposed in the Municipal Sanitation Plan and the Plan of ljuí River Basin, major environmental problems in the basin were raised, also defining services and indicating possible environmental benefits. PEPSA proposes an integrated analysis of policies related to water resources, linking them with the goals and objectives of the plans analyzed. In order to accomplish the proposed actions, PEPSA suggests, after identifying possible funding sources, putting together a fund to pay for environmental services. The sistematically organized PEPSA can be understood as a base tool for effective actions and goals proposed in different plans and programs, and thus, for the implementation of public policies.
\end{abstract}

Keywords: environmental services; payment; watershed; integrated water resources management; arroyo Itaquarinchim.

\section{INTRODUÇÃO}

Serviços ambientais são aqueles proporcionados ao ser humano pelo meio ambiente, resultados das complexas interações entre os componentes bióticos e abióticos dos ecossistemas, e os providos por ecossistemas manejados ativamente pelo homem. Entre os diversos instrumentos da política ambiental (BRASIL, 2009) que objetivam preservar esses serviços, o instrumento de Pagamento por Serviços Ambientais (PSA) apresenta-se como promissor para uma gestão ambiental exitosa e que, ao mesmo tempo, gere novas fontes de renda para avançar na proteção do meio ambiente.
De acordo com Altmann (2010), o PSA é um instrumento de valoração ambiental entre provedores e beneficiários, por meio do qual estes remuneram os primeiros pela garantia do fluxo contínuo de determinado serviço ambiental. A partir dessas relações de PSA, são internalizados os custos e benefícios relacionados aos serviços ambientais na contabilidade de atividades produtivas e de conservação, seguindo o conceito de poluidor-pagador e provedor-recebedor (BRASIL, 2011).

Nesse sentido, autores como Maynard, James e Davidson (2010) defendem que a abordagem de PSA, se bem estruturada, pode ser

'Universidade Federal do Rio Grande do Sul - Porto Alegre (RS), Brasil.

*Autor correspondente: dieterw@iph.ufrgs.br

Recebido: 07/03/2O14 - Aceito: 08/07/2O18 - Reg. ABES: 131637 
implantada como ferramenta facilitadora para discussão entre governo e sociedade acerca dos desafios e das oportunidades para as interações entre homem e ambiente, podendo ser uma base sólida para nortear políticas públicas e definir ações estratégicas.

Compreendendo a importância de instituir programas que valorizem os serviços ambientais, objetiva-se, com o presente trabalho, desenvolver um Plano Estratégico de Pagamento por Serviços Ambientais (PEPSA), elencando os principais serviços ambientais relativos à manutenção da qualidade da água e do solo na bacia hidrográfica do arroio Itaquarinchim, localizada no município de Santo Ângelo (RS). Ainda se pretendem identificar possíveis fontes de auxílio para a formatação de um fundo, do qual seriam provenientes os recursos para a aplicação do PEPSA, com base na análise integrada das políticas relacionadas aos recursos hídricos, correlacionando metas e objetivos.

\section{METODOLOGIA}

A área de estudo deste trabalho compreende a bacia hidrográfica do arroio Itaquarinchim, com aproximadamente $60 \mathrm{~km}^{2}$, na qual está inserida grande parte da área urbana do município de Santo Ângelo. Essa bacia faz parte da bacia hidrográfica do rio Ijuí e pertence à região hidrográfica do rio Uruguai (SEMA, 2011). A Figura 1 apresenta o mapa da imagem de satélite do município de Santo Ângelo e a bacia do arroio Itaquarinchim com a hidrografia (ANA, 2013).

Para a elaboração do PEPSA, realizou-se primeiramente o diagnóstico ambiental da bacia hidrográfica. Essa investigação foi feita em duas etapas: a primeira compreendeu as análises do Plano Municipal de Saneamento Básico de Santo Ângelo (SANTO ÂNGELO, 2011b), do Diagnóstico da Bacia Hidrográfica do Rio Ijuí - realizado em 2011 para a elaboração do Plano de Bacia (SEMA, 2011) - e do documento Panorama da Qualidade das

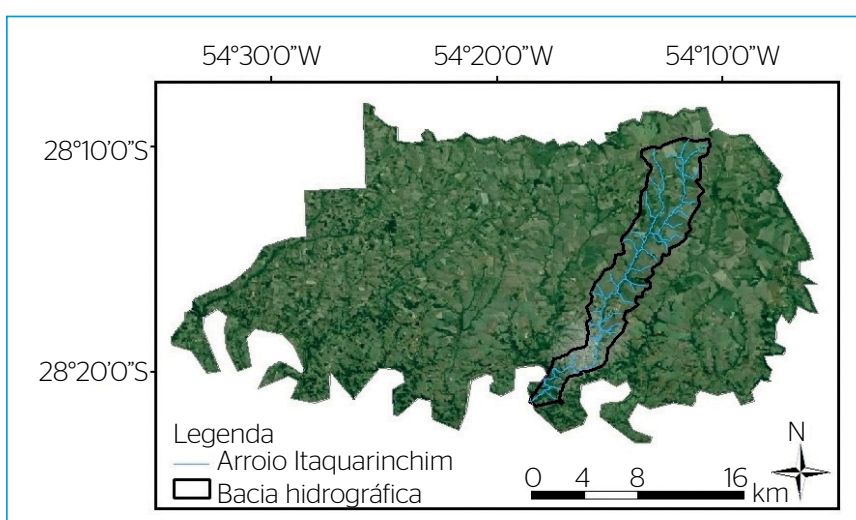

Figura 1 - Mapa da imagem de satélite do município de Santo Ângelo e da bacia hidrográfica do arroio Itaquarinchim com hidrografia.
Águas Superficiais do Brasil (ANA, 2012); e a segunda contemplou uma visita à bacia para avaliar o estado atual do local. A partir das informações obtidas, foram definidos os principais problemas ambientais existentes na bacia do arroio Itaquarinchim e recomendados possíveis serviços ambientais que podem ser colocados em prática nessa região.

Após a conclusão das etapas descritas anteriormente, foi realizada uma apreciação com o objetivo de integrar o PEPSA do arroio Itaquarinchim com o Plano de Recursos Hídricos da Bacia Hidrográfica do Rio Ijuí e com o Plano Municipal de Saneamento Básico de Santo Ângelo, levando ainda em consideração o Plano Diretor (PD) do Município e projetos de outros setores, como o Programa Despoluição de Bacias Hidrográficas e o Plano ABC. Essa etapa visou discutir sobre de que forma pode-se definir e operacionalizar o fundo de PSA.

\section{RESULTADOS E DISCUSSÃO}

\section{Diagnóstico ambiental da bacia hidrográfica}

O diagnóstico apresentado a seguir é resultado de revisão bibliográfica, análise de documentos e visitas técnicas à bacia do arroio Itaquarinchim. Foram observados alguns aspectos ambientais e identificados como contribuintes para a degradação da qualidade da água no arroio Itaquarinchim:

- as áreas de mata ciliar apresentavam-se em geral preservadas na área rural, havendo alguns pontos de falhas. $\mathrm{Na}$ área urbana, o cenário era diferente, havendo desmatamento em diversos locais, habitações em áreas de preservação permanente (APP) e presença de espécies vegetais exóticas;

- foi visualizado que a maior parte das áreas rurais é destinada para a agricultura (trigo, canola, soja), onde se utilizam fertilizantes e agrotóxicos. Além disso, existe a atividade de suinocultura na bacia;

- na área urbana, foi visualizada uma intensa quantidade de resíduos dispostos inadequadamente nas margens do arroio, bem como canalizações ilegais de efluente cloacal.

Quanto às análises de qualidade da água, em um estudo realizado pelo Comitê da Bacia Hidrográfica do Rio Ijuí, no qual foram monitorados os parâmetros de temperatura, $\mathrm{pH}$, cor, turbidez, oxigênio dissolvido $(\mathrm{OD})$, demanda bioquímica de oxigênio $\left(\mathrm{DBO}_{5}\right)$ e coliformes termotolerantes, o arroio Itaquarinchim é classificado como classe 1 na nascente monitorada (nascente do arroio Comandaí), classe 2 no ponto anterior à captação da Companhia Riograndense de Saneamento (CORSAN) e classe 4 na área urbana, de acordo com a Resolução CONAMA no 357/2005 (BRASIL, 2005). Os parâmetros responsáveis por essa classificação foram principalmente coliformes 
termotolerantes, $\mathrm{DBO}_{5}$ e $\mathrm{OD}$, que estavam com valores críticos (SANTOS et al., 2011).

As localizações aproximadas dos locais visitados estão apresentadas na Figura 2, bem como alguns registros fotográficos.

\section{Levantamento dos serviços ambientais}

De acordo com os problemas levantados na bacia hidrográfica do arroio Itaquarinchim e com os objetivos propostos neste trabalho, os serviços ambientais de interesse para o projeto são os de proteção de bacias hidrográficas e de proteção de solos. Nesse contexto, o levantamento das ações, apresentado nos Quadros 1 e 2, preconizou a utilização de uma estratégia direcionada para conter a poluição e manter regularizada a vazão dos recursos hídricos, bem como para manter a capacidade produtiva e combater os processos erosivos do solo. Por exemplo, na categoria do serviço ambiental Serviços de Proteção da Água e do Solo, a ação de reflorestamento da mata ciliar (APP) ao longo do arroio Itaquarinchim e de seus afluentes representa os Serviços Ambientais de Interesse de melhoria da qualidade da água e a manutenção do solo. Esses serviços ambientais irão criar filtros naturais, auxiliando na decomposição e redução de poluentes, e irão proteger as margens contra a erosão.

\section{Análise integrada}

Para a implantação e o funcionamento de um PSA, é necessária a criação de um fundo que possibilite a provisão de capital para a realização das atividades. Esse fundo seria gerido por um comitê técnico do PEPSA, que teria como responsabilidades o gerenciamento do projeto e o acompanhamento das ações, estipulando, de acordo com as metas e os objetivos elencados, prioridades de ação e quantias necessárias a serem levantadas por ele.

O PEPSA, delineado na Figura 3, pode ser compreendido como ferramenta base para a efetivação de ações e metas propostas em diferentes planos e programas e, dessa forma, gerenciar a interface entre a temática do meio ambiente, dos recursos hídricos, de programas pela proteção climática, do planejamento das cidades e do saneamento. Entre os planos e programas vigentes, poderiam ser fonte de recursos do fundo do PEPSA em questão o Programa Despoluição de Bacias Hidrográficas (PRODES), da Agência Nacional de Águas (ANA);

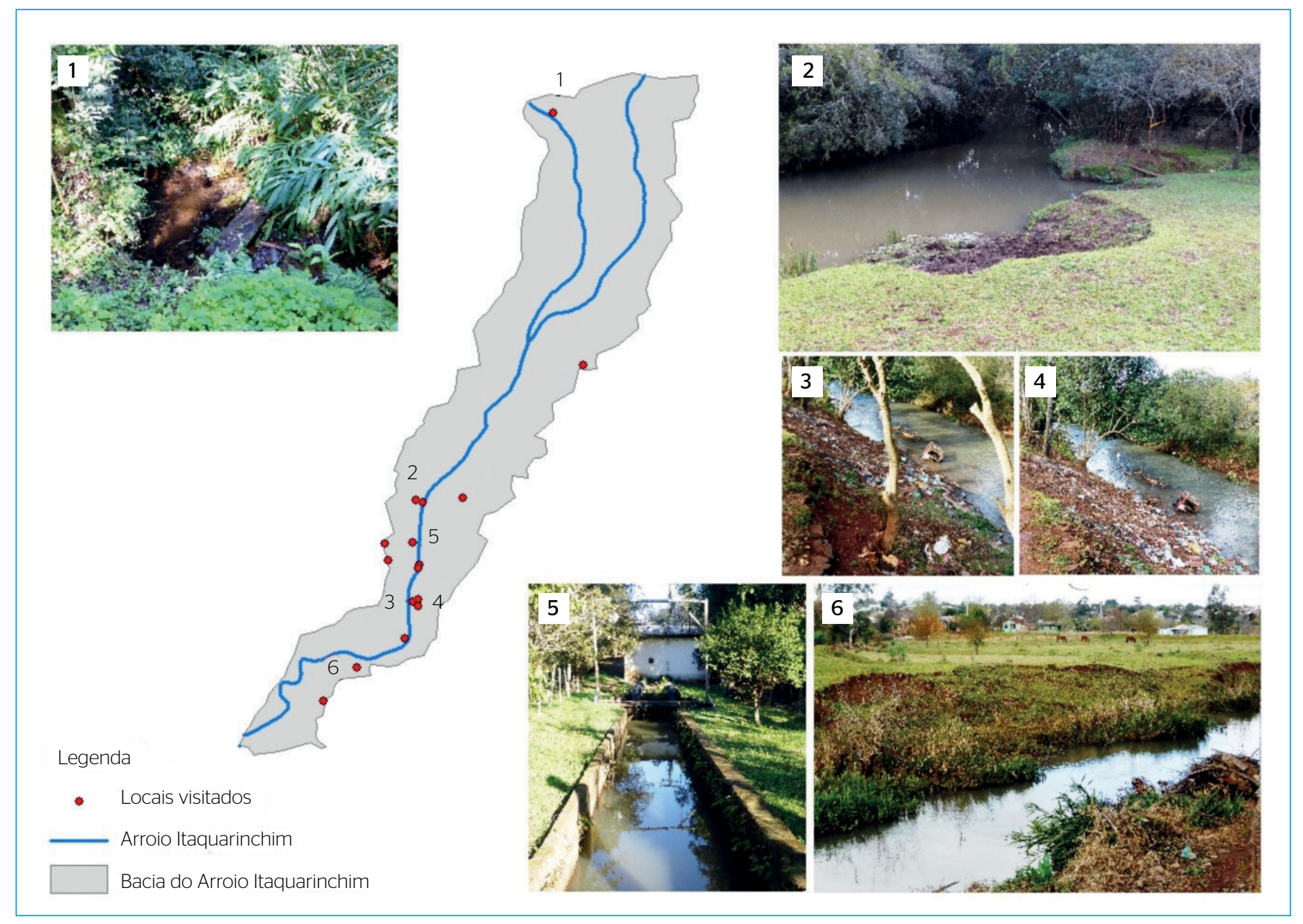

Figura 2 - Locais visitados ao longo da bacia do arroio Itaquarinchim. 
o Plano de Agricultura de Baixa Emissão de Carbono (Plano ABC), do Ministério da Agricultura, conforme Decreto n 7.390/2010 (BRASIL, 2016); o Plano de Recursos Hídricos (PRH), nesse caso do Rio Ijuí, a ser elaborado e gerido pelo Comitê de Bacia Hidrográfica do Rio Ijuí, conforme Lei no 9.433/1997 (BRASIL, 1997); e o Plano Municipal de Saneamento Básico (PMSB), nesse caso, do município de Santo Ângelo, conforme Lei $n^{\circ} 11.445 / 2007$ (BRASIL, 2007), por intermédio do Fundo Municipal de Gestão Compartilhada de Santo Ângelo (FMGC).

O PRODES, criado pela ANA em 2001, consiste no pagamento pelo esgoto efetivamente tratado, desde que cumpridas as metas de remoção de carga poluidora (ANA, 2018). Como o valor pago pelo
PRODES é destinado diretamente ao prestador de serviço, a CORSAN, esta poderia pleitear a verba disponibilizada pelo programa após a adequação aos critérios de elegibilidade e realização de ampliações, complementações e melhorias operacionais na ETE na modalidade de compensação. Dessa maneira, o programa seria um contribuinte indireto ao fundo do PEPSA.

O Plano ABC é um dos planos setoriais do Governo Federal de mitigação e adaptação às mudanças climáticas. Este foi estabelecido de acordo com o Art. $3^{\circ}$ do Decreto $n^{\circ} 7.390 / 2010$ e se apresenta como um dos instrumentos da Política Nacional sobre Mudança do Clima (PNMC) instituída pelo referido decreto. Nesse plano, existem três programas que, além de atender aos

Quadro 1 - Propostas de serviços ambientais na área rural da bacia hidrográfica do arroio Itaquarinchim.

\begin{tabular}{|c|c|c|c|}
\hline $\begin{array}{l}\text { Categoria } \\
\text { do serviço } \\
\text { ambiental }\end{array}$ & Ação & $\begin{array}{l}\text { Serviço } \\
\text { ambiental de } \\
\text { interesse }\end{array}$ & Como a ação poderá prestar o serviço ambiental? \\
\hline \multirow{15}{*}{$\begin{array}{l}\text { Serviços } \\
\text { de } \\
\text { proteção } \\
\text { da água e } \\
\text { do solo }\end{array}$} & \multirow{2}{*}{$\begin{array}{l}\text { Reflorestamento de mata } \\
\text { ciliar (APP) ao longo do } \\
\text { arroio Itaquarinchim e } \\
\quad \text { seus afluentes }\end{array}$} & $\begin{array}{l}\text { Purificação } \\
\text { da água }\end{array}$ & $\begin{array}{l}\text { A revegetação com espécies nativas cria filtros naturais, auxiliando na decomposição e } \\
\text { redução de poluentes. }\end{array}$ \\
\hline & & $\begin{array}{l}\text { Manutenção } \\
\text { do solo }\end{array}$ & $\begin{array}{c}\text { A revegetação com espécies nativas protege as margens do rio contra a erosão pelo } \\
\text { desenvolvimento e pela manutenção das raízes. }\end{array}$ \\
\hline & \multirow{3}{*}{$\begin{array}{l}\text { Proteção da mata ciliar } \\
\text { (APP) ao longo do rio } \\
\text { Itaquarinchim e seus } \\
\quad \text { afluentes }\end{array}$} & $\begin{array}{l}\text { Purificação } \\
\text { da água }\end{array}$ & $\begin{array}{l}\text { A proteção das matas ciliares contribui com a manutenção dos filtros naturais que auxiliem } \\
\text { na decomposição e redução de poluentes. }\end{array}$ \\
\hline & & $\begin{array}{l}\text { Regulação do } \\
\text { fluxo de água }\end{array}$ & $\begin{array}{c}\text { As matas ciliares, ao reter a água da chuva, aumentando a infiltração da água no } \\
\text { solo e liberando-a gradativamente para o corpo d’água, influencia diretamente na } \\
\text { manutenção da vazão nos rios. }\end{array}$ \\
\hline & & $\begin{array}{l}\text { Manutenção } \\
\text { do solo }\end{array}$ & $\begin{array}{l}\text { As matas ciliares protegem as margens do rio contra a erosão pelo } \\
\text { desenvolvimento e pela manutenção das raízes, contendo as enxurradas e } \\
\text { reduzindo o assoreamento da calha do rio. }\end{array}$ \\
\hline & \multirow{2}{*}{$\begin{array}{l}\text { Integração lavoura, } \\
\text { pecuária e floresta }\end{array}$} & $\begin{array}{l}\text { Purificação } \\
\text { da água }\end{array}$ & $\begin{array}{c}\text { Ao prever a rotação de culturas, sistema que melhora as características do solo e torna as } \\
\text { espécies vegetais mais resistentes, resulta na redução de utilização de insumos, fertilizantes } \\
\text { e agrotóxicos. }\end{array}$ \\
\hline & & $\begin{array}{l}\text { Manutenção } \\
\text { do solo }\end{array}$ & A rotação evita o desgaste excessivo do solo, diminuindo o potencial erosivo. \\
\hline & \multirow{3}{*}{$\begin{array}{l}\text { Remoção das residências } \\
\text { em área de mata ciliar e } \\
\text { reflorestamento dessas } \\
\text { áreas com espécies } \\
\text { arbóreas nativas. }\end{array}$} & $\begin{array}{l}\text { Purificação } \\
\text { da água }\end{array}$ & \multirow{3}{*}{$\begin{array}{c}\text { Ao auxiliar a realocação dos moradores que residem em área de mata ciliar (APP) para } \\
\text { locais mais adequados e instituir um programa de recuperação dessas margens, essa } \\
\text { ação contribuirá com a manutenção dos filtros naturais que auxiliem na decomposição } \\
\text { e redução de poluentes e com a proteção das margens do rio contra a erosão pelo } \\
\text { desenvolvimento e pela manutenção das raízes. A vegetação, ao reter a água da } \\
\text { chuva, aumentando a infiltração da água no solo e liberando-a gradativamente para o } \\
\text { corpo d’água, influencia também na manutenção da vazão nos rios. Adicionalmente, } \\
\text { proporcionará áreas de lazer para a população. }\end{array}$} \\
\hline & & $\begin{array}{l}\text { Regulação do } \\
\text { fluxo de água }\end{array}$ & \\
\hline & & $\begin{array}{l}\text { Manutenção } \\
\text { do solo }\end{array}$ & \\
\hline & \multirow{2}{*}{ Plantio direto } & $\begin{array}{l}\text { Purificação } \\
\text { da água }\end{array}$ & $\begin{array}{c}\text { O plantio direto ao prever a rotação de culturas, sistema que melhora as } \\
\text { características do solo e torna as espécies vegetais mais resistentes, resulta na } \\
\text { redução de utilização de insumos. }\end{array}$ \\
\hline & & $\begin{array}{l}\text { Manutenção } \\
\text { do solo }\end{array}$ & $\begin{array}{l}\text { No plantio direto é prevista a mobilização mínima de solo, o que preserva a estrutura } \\
\text { do solo, reduz perdas de água por escoamento superficial e, consequentemente, } \\
\text { reduz perdas de solo por erosão. }\end{array}$ \\
\hline & \multirow{3}{*}{$\begin{array}{l}\text { Somente para pequena } \\
\text { propriedade: exploração } \\
\text { agroflorestal sustentável } \\
\text { em margens do rio (APP)'1 }\end{array}$} & $\begin{array}{l}\text { Purificação } \\
\text { da água }\end{array}$ & \multirow{3}{*}{$\begin{array}{l}\text { A revegetação em APP com espécies nativas de interesse comercial juntamente com } \\
\text { culturas florestais contribui com a manutenção dos filtros naturais que auxiliem na } \\
\text { decomposição e redução de poluentes e com a proteção das margens do rio contra a } \\
\text { erosão pelo desenvolvimento e pela manutenção das raízes. A vegetação, ao reter a água } \\
\text { da chuva, aumentando a infiltração da água no solo e liberando-a gradativamente para o } \\
\text { corpo d'água, influencia diretamente na manutenção da vazão nos rios. }\end{array}$} \\
\hline & & $\begin{array}{l}\text { Regulação do } \\
\text { fluxo de água }\end{array}$ & \\
\hline & & $\begin{array}{l}\text { Manutenção } \\
\text { do solo }\end{array}$ & \\
\hline
\end{tabular}

APP: área de proteçăo permanente; 'prática permitida conforme Artigo $8^{\circ}$ da Lei no 12.651, de 25 de maio de 2012. 
Quadro 2 - Propostas de serviços ambientais na área rural da bacia hidrográfica do arroio Itaquarinchim.

\begin{tabular}{|c|c|c|c|}
\hline $\begin{array}{l}\text { Categoria } \\
\text { do serviço } \\
\text { ambiental }\end{array}$ & Ação & $\begin{array}{c}\text { Serviço } \\
\text { Ambiental de } \\
\text { Interesse }\end{array}$ & Como a ação poderá prestar o serviço ambiental? \\
\hline \multirow{5}{*}{$\begin{array}{l}\text { Serviços } \\
\text { de } \\
\text { proteção } \\
\text { da água }\end{array}$} & \multirow{2}{*}{$\begin{array}{c}\text { Preservação de nascentes } \\
\text { (APP) do rio Itaquarinchim } \\
\text { e seus afluentes }\end{array}$} & $\begin{array}{l}\text { Purificação } \\
\text { da água }\end{array}$ & \multirow{2}{*}{$\begin{array}{l}\text { A preservação das nascentes contribui para a proteção das fontes de origem dos cursos } \\
\text { hídricos contra foco de poluição e para o provimento regular de água em qualidade. }\end{array}$} \\
\hline & & $\begin{array}{l}\text { Regulação do } \\
\text { fluxo de água }\end{array}$ & \\
\hline & $\begin{array}{l}\text { Tratamento de efluentes } \\
\text { domésticos }\end{array}$ & $\begin{array}{l}\text { Purificação } \\
\text { da água }\end{array}$ & $\begin{array}{l}\text { O tratamento de efluentes domésticos diminui drasticamente a carga orgânica lançada nos } \\
\text { cursos hídricos, contribuindo para a qualidade da água dos mananciais. }\end{array}$ \\
\hline & $\begin{array}{l}\text { Tratamento de efluentes } \\
\text { de origem animal }\end{array}$ & $\begin{array}{l}\text { Purificação } \\
\text { da água }\end{array}$ & $\begin{array}{l}\text { O tratamento de efluentes de origem animal diminui drasticamente a carga orgânica } \\
\text { lançada nos cursos hídricos, contribuindo para a qualidade da água dos mananciais. }\end{array}$ \\
\hline & Adubação verde/orgânica & $\begin{array}{l}\text { Purificação } \\
\text { da água }\end{array}$ & $\begin{array}{l}\text { A não aplicação de produtos químicos (insumos, fertilizantes e agrotóxicos) no solo evita a } \\
\text { contaminação dos recursos hídricos com tais poluentes. }\end{array}$ \\
\hline \multirow{3}{*}{$\begin{array}{l}\text { Serviços } \\
\text { de } \\
\text { proteção } \\
\text { do solo }\end{array}$} & $\begin{array}{l}\text { Emprego de curvas de } \\
\text { níveis }\end{array}$ & $\begin{array}{l}\text { Manutenção } \\
\text { do solo }\end{array}$ & $\begin{array}{l}\text { Prática que visa ao controle do escoamento superficial e aumento da infiltração de água no solo, } \\
\text { reduzindo os danos da erosão e, consequentemente, evitando a sedimentação nos mananciais. }\end{array}$ \\
\hline & $\begin{array}{c}\text { Construção de pequenas } \\
\text { bacias de detenção na } \\
\text { área rural }\end{array}$ & $\begin{array}{l}\text { Manutenção } \\
\text { do solo }\end{array}$ & $\begin{array}{l}\text { Prática que visa ao aumento da infiltração de água no solo, reduzindo os danos da erosão } \\
\text { e, por conseguinte, evitando a sedimentação nos mananciais. }\end{array}$ \\
\hline & $\begin{array}{c}\text { Adequação de estradas e } \\
\text { corredores }\end{array}$ & $\begin{array}{l}\text { Manutenção } \\
\text { do solo }\end{array}$ & $\begin{array}{c}\text { As obras a serem realizadas nas estradas (pequenas bacias de detenção, quebra de } \\
\text { barranco, elevação e correção do leito etc.) podem vir a proporcionar um melhor controle } \\
\text { da erosão minimizando a sedimentação nos mananciais. }\end{array}$ \\
\hline
\end{tabular}

APP: área de proteção permanente.

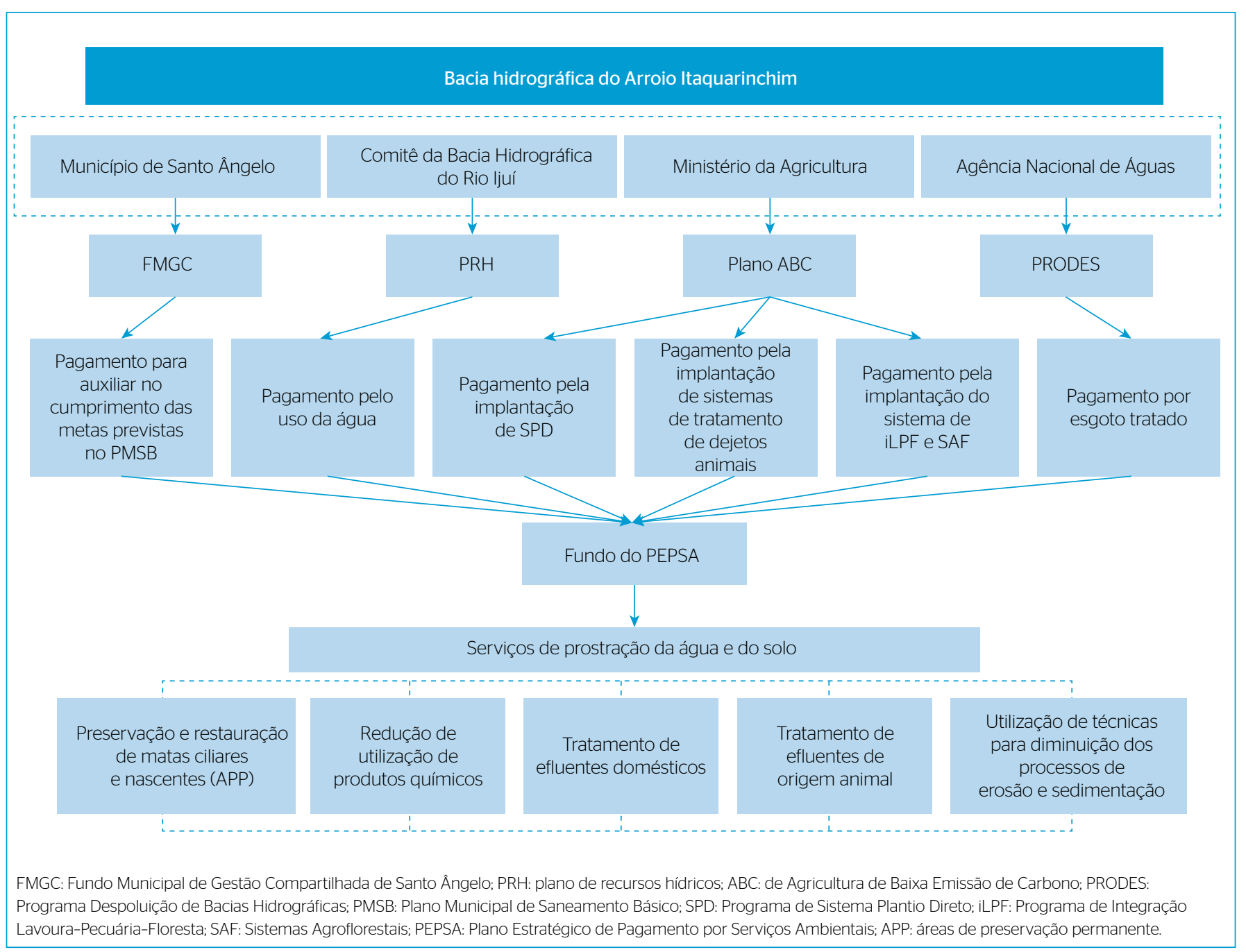

Figura 3 - Fluxograma do Plano Estratégico de Pagamento por Serviços Ambientais. 
objetivos de reduzir as emissões de gases do efeito estufa (GEE), também produzem benefícios em relação à manutenção do solo e dos recursos hídricos, ou seja, vão ao encontro dos objetivos do PEPSA. São eles: Programa de Sistema Plantio Direto (SPD), Programa de Integração Lavoura-Pecuária-Floresta (iLPF) e Sistemas Agroflorestais (SAF) e Programa de Tratamento de Dejetos Animais (BRASIL, 2016). Assim, a utilização por propriedades rurais de qualquer um dos programas citados tornaria o Plano ABC parte integrante do PEPSA e, consequentemente, um dos contribuintes para o fundo.

O Plano de Bacia Hidrográfica $(\mathrm{PBH})$ da bacia hidrográfica do Rio Ijuí tem por objetivo definir os futuros usos da água na bacia e, a partir destes, determinar a classe de cada rio. $\mathrm{O}$ arroio Itaquarinchim, enquadrado na classe II, conforme Lei dos Recursos Hídricos (Lei no 9.433/1997), apresenta-se fora do seu enquadramento antes de desembocar no rio Ijuí. Dessa forma, é interesse - e dever do Comitê de Bacia - harmonizar os usos pretendidos com a qualidade das águas, elencando ações que promovam a melhoria da qualidade do arroio. A Lei dos Recursos Hídricos prevê, em seu Art. $5^{\circ}$, a cobrança pelo uso dos recursos hídricos, e os valores arrecadados poderiam ser revertidos ao fundo como forma de auxílio ao cumprimento das metas previstas no $\mathrm{PRH}$, tornando-o outro importante integrante do PEPSA. Tal prática, de investir os valores arrecadados em programas de melhoria da qualidade dos recursos hídricos, já é prevista pela Lei dos Recursos Hídricos, quando, em seu Art. 19 , inciso III, é apresentado que um dos objetivos da cobrança pelo uso dos recursos hídricos é obter recursos financeiros para o financiamento de programas e intervenções contemplados nos planos de recursos hídricos.

Quando o foco da análise é direcionado ao âmbito municipal, entende-se que o município de Santo Ângelo será o maior beneficiário com a implantação do PEPSA. Este, ao objetivar o planejamento da destinação e arrecadação dos recursos a serem investidos na manutenção e preservação dos serviços ambientais no arroio Itaquarinchim, vem ao encontro de metas e ações já levantadas pelo município no PD, instituído pela Lei Municipal no 3.526, de 27 de junho de 2011 (SANTO ÂNGELO, 2011a), e no PMSB.

Ao analisarmos os serviços ambientais e as ações propostas neste trabalho com as diretrizes apontadas no PD e, em especial, com as metas elencadas no PMSB, percebe-se uma convergência de objetivos. O PD, em seu Art. $29^{\circ}$, inciso V, ressalta a necessidade de promover incentivos fiscais e programas de apoio para pessoas que possuem imóveis em APP, auxiliando na manutenção, preservação e proteção. Por sua vez, o PMSB elenca várias metas e ações que poderiam ser concretizadas com a implementação do PEPSA, como:

- programa de proteção de mananciais hídricos, margens arroios, áreas ciliares;
- promoção de incentivos fiscais e programas de apoio às pessoas físicas que possuam imóveis em APP e que preservam essa área;

- incentivo ao destino correto de dejetos e águas servidas das propriedades no meio rural;

- coibição do lançamento de esgotos sanitário e industrial em redes pluviais e nos recursos hídricos;

- previsão, no planejamento urbanístico da cidade, a reserva de áreas junto às margens dos arroios na zona urbana, visando à construção de parques lineares ou APP.

No PMSB, também são elencadas ações necessárias para o adequado gerenciamento dos serviços sanitários no município, dos quais podemos citar o monitoramento da qualidade da água, a identificação e os mapeamentos dos pontos críticos de escoamento de água e das nascentes. O PEPSA poderia auxiliar na concretização dessas ações, uma vez que estas são necessárias para a gestão de projetos de serviços ambientais e para o acompanhamento de seus resultados.

A parcela de recursos a ser destinada pelo município ao fundo do PEPSA viria do FMGC, criado pela Lei Municipal $n^{\circ} 3.454$, de 8 de outubro de 2010 (SANTO ÂNGELO, 2010), que tem como finalidade a arrecadação de recursos a serem direcionados ao saneamento básico. Esse fundo municipal, ao destinar uma parcela de seus recursos ao fundo do PEPSA, contribuirá para a implementação deste e para a concretização de ações e de metas elencadas no PMSB.

\section{CONCLUSÕES}

Os principais problemas ambientais diagnosticados na bacia do arroio Itaquarinchim são: a não preservação da cobertura vegetal (mata ciliar), o uso inadequado do solo (erosão e uso de agrotóxicos na agricultura) e os efluentes urbanos e de origem animal.

O PEPSA propõe-se a proteger a qualidade da água e do solo por meio de ações e indicar como estas podem prestar os serviços ambientais. Ele constitui uma ferramenta base para a efetivação de ações e metas propostas em diferentes planos e programas e, dessa forma, gerenciar a interface entre a temática do meio ambiente, dos recursos hídricos, de programas pela proteção climática, do planejamento das cidades e do saneamento.

Considerando o financiamento das ações propostas, o PEPSA sugere a formatação de um fundo para pagamento dos serviços ambientais, cujos recursos viriam dos planos PRODES, ABC, PD, PMSB, CORSAN e PBH.

O gerenciamento integrado dos planos e a cooperação entre a ANA, o Comitê de Bacia Hidrográfica, o município, a companhia de saneamento e as políticas públicas são imprescindíveis para alcançar os resultados pretendidos e garantir que as ações propostas nos planos sejam efetivadas. 


\section{REFERÊNCIAS}

AGÊNCIA NACIONAL DE ÁGUAS (ANA). Bacia 7 (Rio Uruguai). Disponível em: <http://hidroweb.ana.gov.br/HidroWeb. asp?Tocltem=4100>. Acesso em: jun. 2013.

(2012) Panorama da qualidade das águas superficiais do Brasil. Brasília: ANA.

Programa Despoluição de Bacias Hidrográficas - Prodes. Brasil: ANA. Disponível em: <http://www.ana.gov.br/prodes/>. Acesso em: 16 jul. 2018.

ALTMANN, A. (2010) Pagamento por serviços ambientais: aspectos jurídicos para a sua aplicação no Brasil. In: CONGRESSO INTERNACIONAL DE DIREITO AMBIENTAL, FLORESTAS, MUDANÇAS CLIMÁTICAS E SERVIÇOS ECOLÓGICOS, 14., 2010. Anais... São Paulo: Imprensa Oficial.

BRASIL. (1997) Lei no 9.433, de 8 de janeiro de 1997. Institui a Política Nacional deRecursos Hídricos, cria oSistema Nacional de Gerenciamento de Recursos Hídricos, regulamenta o inciso XIX do art. 21 da Constituição Federal, e altera o art. 10 da Lei no 8.001, de 13 de março de 1990, que modificou a Lei no 7990, de 28 de dezembro de 1989. Diário Oficial [da] Republica Federativa do Brasil, Brasília, Seção 1, p. 470.

(2005) Conselho Nacional do Meio Ambiente. Resolução n× 357, de 17 de março de 2005. Dispõe sobre a classificação dos corpos de água e diretrizes ambientais para o seu enquadramento, bem como estabelece as condições e padrões de lançamento de efluentes, e dá outras providências. Brasília: Ministério do Meio Ambiente. 23 p.

(2007) Lei n. ${ }^{\circ}$ 11.445, de 5 de janeiro de 2007. Estabelece diretrizes nacionais para o saneamento básico; altera as Leis no 6.766, de 19 de dezembro de 1979, no 8.036, de 11 de maio de 1990, n० 8.666, de 21 de junho de 1993, n० 8.987, de 13 de fevereiro de 1995; revoga a Lei no 6.528, de 11 de maio de 1978; e dá outras providências. Diário Oficial [da] Republica Federativa do Brasil, Brasília, Seção 1, p. 3.

(2009) Projeto de Lei no 5.487, de 24 de junho de 2009. Institui a Política Nacional dos Serviços Ambientais, o Programa Federal de Pagamento por Serviços Ambientais, estabelece formas de controle e financiamento desse Programa, e dá outras providências. Brasília.
. (2011) Ministério do Meio Ambiente. Pagamentos por Serviços Ambientais na Mata Atlântica: lições aprendidas e desafios. Brasília: Ministério do Meio Ambiente.

(2016) Ministério da Agricultura, Pecuária e Abastecimento. Plano ABC. Disponível em: <http://www.agricultura.gov.br/assuntos/ sustentabilidade/plano-abc>. Acesso em: 16 jul. 2018.

MAYNARD, S.; JAMES, D.; DAVIDSON, A. (2010) The Development of an Ecosystem Services Framework for South East Queensland. Environmental Management, v. 45, n. 5, p. 881-895. https://doi. org/10.1007/s00267-010-9428-z

SANTO ÂNGELO. (2010) Lei no 3.454, de 8 de outubro de 2010. Cria o Fundo Municipal de Gestão Compartilhada de Santo Ângelo. Disponível em: <https://pmsantoangelo.abase.com.br/site/ leis/32951-cria-o-fundo-municipal-de-gestao-compartilhada-desanto-angelo>. Acesso em: 16 jul. 2018.

(2011a) Lei no 3.526, de 27 de junho de 2011. Institui o Plano Diretor de Desenvolvimento Integrado do Município de Santo Ângelo e dá outras providências. Disponível em: <https:// pmsantoangelo.abase.com.br/site/leis/37943-institui-o-planodiretor-de-desenvolvimento-integrado-do-municipio-de-santoangelo>. Acesso em: 16 jul. 2018.

(2011b) Plano Municipal de Saneamento Básico Participativo do Município de Santo Ângelo - RS. Instituto de Pesquisas Hidráulicas da Universidade Federal do Rio Grande do Sul (IPH/ UFRGS). Porto Alegre.

SANTOS, Z.S.; GRAVE, G.; BRONSTRUP, C.; VEIGA, F.; LAUSMANN, A.M. (2011) Bacia Hidrográfica do Rio Itaquarinchim, um bem a ser preservado na construção de um futuro com desenvolvimento e qualidade de vida. In: BACIA HIDROGRÁFICA DO RIO IJUI: Construções e Aprendizados. Santo Ângelo. p. 119-132.

SECRETARIA ESTADUAL DE MEIO AMBIENTE (SEMA). (2O11) Processo de Planejamento da Bacia Hidrográfica do Rio ljuí - Fases $A$ e B. SEMA. 